\title{
SYNTHESIS, STRUCTURE AND PHOTOLUMINESCENT PROPERTY OF A CADMIUM COMPLEX WITH 2,4-DICHLOROPHENOXYACETIC ACID
}

\author{
YONG-HONG ZHOU \\ School of Chemistry and Material Science, Huaibei Normal University, Huaibei, P. R. China \\ Address correspondence to Yong-Hong Zhou, School of Chemistry and Material Science, Huaibei Normal University, Huaibei, P. R. China.
}

\begin{abstract}
A new complex $\left[\mathrm{Cd}(2,4-\mathrm{D})_{2}(\mathrm{Im})_{2}\left(\mathrm{H}_{2} \mathrm{O}\right)_{2}\right]$ with 2,4-dichlorophenoxyacetic acid (2,4-DH) and imidazole $(\mathrm{Im})$ as ligands has been synthesized and characterized by elemental analysis, IR spectrometry and single-crystal X-ray diffraction. The Cd(II) atom is coordinated in a distorted octahedral geometry, which is defined by two $\mathrm{O}$ atoms from two monodentate 2,4-dichlorophenoxyacetate ligands, two $\mathrm{N}$ atoms from two imidazole ligands and two water molecules. Intermolecular $\mathrm{O}-\mathrm{H} \cdots \mathrm{O}$ hydrogen bonds form chains, which are connected by $\mathrm{N}-\mathrm{H} \cdots \mathrm{O}$ hydrogen bonds, generating a sheet structure. The molecules are further assembled by $\pi \cdots \pi$ stacking interactions to form a two dimensional supramolecular network.
\end{abstract}

Keywords: Crystal structure; 2,4-dichlorophenoxyacetic acid; Cadmium(II) complex.

\section{INTRODUCTION}

Recently, much attention has been paid to carboxyl complexes due to their attractive structures and promising applications for catalysis, gas storage, magnetic materials and optoelectronics. ${ }^{1-2}$ Generally, the design or selection of suitable ligands having certain features, such as functionality and versatile binding modes, plays an important role in determining the topologies and properties of carboxyl complexes. In the past few years, extensive studies in this field have been focused on the utilization of rigid aromatic carboxylic acids as ligands. Comparatively, flexible carboxylic ligands have not been studied much, which is probably due to their varied geometries and conformations, and this often make it difficult to forecast and control the final structures of the expected products. ${ }^{3}$ To better understand the coordination chemistry of flexible carboxylic ligands and prepare desired complexes with predictable structures and properties, it is necessary to exploit flexible carboxylic acid ligands. 2,4-Dichlorophenoxyacetic acid (2,4-DH) is a member of arylcarboxylic acids family, and compounds belonging to it are commonly used as conventional fungicides, plant growth regulators and agricultural hebicides. ${ }^{4}$ In recent years, an increasing interest can be observed on 2,4-DH coordination compounds, including complexes of transition metals such as $\mathrm{Zn}(\mathrm{II})^{5}, \mathrm{Cd}(\mathrm{II}),{ }^{6-7} \mathrm{Cu}(\mathrm{II}),{ }^{8}$ $\mathrm{Mn}(\mathrm{II}),{ }^{9} \mathrm{Co}(\mathrm{II})^{10}$ and $\mathrm{Ni}(\mathrm{II}),{ }^{11}$ alkaline metals such as $\mathrm{Ca}(\mathrm{II}),{ }^{12}$ and lanthanides like $\mathrm{Gd}^{13}$ and Eu. ${ }^{14}$ Several mixed-ligand coordination compounds with 2,4$\mathrm{DH}$ and $\mathrm{N}$-donor ligands, such as phenanthroline, ${ }^{15}$ pyrazole,${ }^{16}$ pyridine, ${ }^{17}$ pyrazine ${ }^{18}$ imidazole ${ }^{19}$ and bipyridine, ${ }^{20}$ are also known, and the results reveal that 2,4-D exhibits versatile binding and coordination modes. These interesting results inspire us to explore the related mixed-ligand coordination systems and to clarify their intrinsic assembly rule. Therefore, we describe here the synthesis, crystal structure and luminescent property of a new Cadium(II) complex $\left[\mathrm{Cd}(2,4-\mathrm{D})_{2}(\mathrm{Im})_{2}\left(\mathrm{H}_{2} \mathrm{O}\right)_{2}\right]$.

\section{EXPERIMENTAL}

2.1 Materials and Physical Measurements

All reagents used in the synthesis were analytical grade. Elemental analyses for $\mathrm{C}, \mathrm{H}$, and $\mathrm{N}$ were performed on a Vario EL III elemental analyzer. The infrared spectra $\left(4000-400 \mathrm{~cm}^{-1}\right)$ were recorded as a $\mathrm{KBr}$ pellet on a Nicolet 170SX FT-IR spectrometer. Luminescence spectrum was obtained with a RF-5301PC fluorescence spectrometer. The crystal structure determination was performed on a Bruker Smart Apex CCD area-detector diffractometer equipped with graphite-monochromatized Mo Ka radiation $(\lambda=0.71073 \AA)$.

2.2 Synthesis of $\left[\mathrm{Cd}(2,4-\mathrm{D})_{2}(\mathrm{Im})_{2}\left(\mathrm{H}_{2} \mathrm{O}\right)_{2}\right](1)$

A mixture of $\mathrm{Cd}\left(\mathrm{NO}_{3}\right)_{2} \cdot 4 \mathrm{H}_{2} \mathrm{O}(0.5 \mathrm{mmol}, 0.15 \mathrm{~g}), 2,4-\mathrm{DH}(1.0 \mathrm{mmol}, 0.22$ g), imidazole $(1.0 \mathrm{mmol}, 0.068 \mathrm{~g}), \mathrm{NaOH}(1.0 \mathrm{mmol}, 0.04 \mathrm{~g})$ and $\mathrm{H}_{2} \mathrm{O}(15 \mathrm{~mL})$ was stirred for $10 \mathrm{~min}$ in air. Then the mixture was transferred to a Teflon-lined autoclave $(25 \mathrm{~mL})$ and kept at $120^{\circ} \mathrm{C}$ for $72 \mathrm{~h}$. After slow cooling to room temperature, pale yellow block crystals were obtained, which were suitable for single-crystal X-ray structure analysis. Anal. Calcd for $\mathrm{C}_{22} \mathrm{H}_{22} \mathrm{CdCl}_{4} \mathrm{~N}_{4} \mathrm{O}_{8}$ : C, $36.43 ; \mathrm{H}, 3.04 ; \mathrm{N}, 7.73$. Found: C, 36.40; H, 3.08; N, 7.76.
2.3 X-ray data collection and structure refinement

Single-crystal data were collected at 298(2) K. The structure was solved by direct methods and successive Fourier difference synthesis (SHELXS-97), and refined using the full-matrix least-squares method on $F^{2}$ with anisotropic thermal parameters for all non-hydrogen atoms (SHELXL-97). ${ }^{[21-22]}$ A summary of the crystallographic data is given in Table 1. Selected bond distances and angles are given in Table 2.

TABLE 1. Crystal data and structure refinement details for $\mathbf{1}$.

\begin{tabular}{|l|l|}
\hline formula & $\mathrm{C}_{22} \mathrm{H}_{22} \mathrm{CdCl}_{4} \mathrm{~N}_{4} \mathrm{O}_{8}$ \\
\hline formula weight & 724.64 \\
\hline Crystal size $\left(\mathrm{mm}^{3}\right)$ & $0.30 \times 0.18 \times 0.15$ \\
\hline Temperature $(\mathrm{K})$ & $298(2)$ \\
\hline crystal system & Monoclinic \\
\hline space group & $P 2_{1} / \mathrm{c}$ \\
\hline$a(\AA)$ & $14.3069(12)$ \\
\hline$b(\AA)$ & $12.7687(11)$ \\
\hline$c(\AA)$ & $7.5954(7)$ \\
\hline$\beta\left({ }^{\circ}\right)$ & $99.5910(10)$ \\
\hline volume/ $\AA^{3}$ & $1368.1(2)$ \\
\hline$Z$ & 2 \\
\hline Density (calculated) $\left(\mathrm{mg} / \mathrm{m}^{3}\right)$ & 1.759 \\
\hline Absorption coefficient $\left(\mathrm{mm}{ }^{-1}\right)$ & 1.242 \\
\hline$\theta$ range for data collection/ $\left({ }^{\circ}\right)$ & 2.89 to 25.02 \\
\hline limiting indices & $-17 £ h £ 14,-15 £ k £ 13,-8 £ l £ 9$ \\
\hline Reflections collected/unique & $6598 / 2403[R($ int $)=0.0373]$ \\
\hline Completeness to $\theta=25.02$ & $99.6 \%$ \\
\hline Refinement method & Full-matrix least-squares on $F^{2}$ \\
\hline$F(000)$ & 724 \\
\hline data / restraints / parameters & $2403 / 0 / 178$ \\
\hline goodness-of-fit on $F^{2}$ & 1.052 \\
\hline final $R$ indices $[I>2 \sigma(I)]$ & $R_{I}=0.0293, w R_{2}=0.0666$ \\
\hline $\mathrm{R}$ indices (all data) & $R_{I}=0.0426, w R_{2}=0.0759$ \\
\hline
\end{tabular}


TABLE 2. Selected bond lengths $(\AA)$ and bond angles $\left({ }^{\circ}\right)$ for $\mathbf{1}$.

\begin{tabular}{|l|c|c|c|}
\hline Cd1-O1 & $2.370(2)$ & C1-O1 & $1.244(4)$ \\
\hline Cd1-O4 & $2.394(2)$ & C1-O2 & $1.249(3)$ \\
\hline Cd1-N1 & $2.238(2)$ & & \\
\hline N1-Cd1-N1A & $180.000(1)$ & N1-Cd1-O1A & $93.09(8)$ \\
\hline N1-Cd1-O1 & $86.91(8)$ & O1A-Cd1-O1 & 180.0 \\
\hline N1-Cd1-O4 & $92.37(9)$ & O1-Cd1-O4 & $103.40(8)$ \\
\hline N1-Cd1-O4A & $87.63(9)$ & O4-Cd1-O4A & 180.0 \\
\hline
\end{tabular}

\section{RESULTS AND DISCUSSION}

\subsection{Infrared spectrum}

The IR spectrum of 1 clearly show both the presence of 2,4-D and coordinated imidazole. The band with the maxima at $3345 \mathrm{~cm}^{-1}$ characteristic for $\mathrm{vOH}$ vibrations confirms the presence of water molecules in the complex. The band at $1734 \mathrm{~cm}^{-1}$ originating from the $\mathrm{RCOOH}$ group, presented in the acid spectrum, is replaced in the spectrum of complex by two bands at 1589 $\mathrm{cm}^{-1}$ and $1358 \mathrm{~cm}^{-1}$, which can be ascribed to the asymmetric and symmetric vibrations of $\mathrm{COO}^{-}$group, respectively. The difference between $v_{\mathrm{as}}(\mathrm{COO})$ and $v(\mathrm{COO})$ is $231 \mathrm{~cm}^{-1}$. According to Kazou Nakamoto, ${ }^{[23]}$ we can infer that the carboxylate groups in $\mathbf{1}$ are in monodentate coordination modes. The strong C-O stretching vibrations at about $1240 \mathrm{~cm}^{-1}$ in the spectrum of 1 suggest that the oxygen atom from phenoxyl may not coordinate to the metal centers. These are in accordance with the results of X-ray diffraction analysis.

3.2 Crystal structural description

As shown in Fig. 1, the Cd(II) atom is coordinated to two oxygen atoms from two 2,4-D ligands and two nitrogen atoms of two imidazole molecules in the equatorial position, and two oxygen atoms of water molecules in the axial position, forming a $\mathrm{CdO}_{4} \mathrm{~N}_{2}$ octahedral geometry. The distance of $\mathrm{Cd}-\mathrm{N}$ is $2.238(2) \AA$, which is shorter than the corresponding values in $\left[\mathrm{Cd}_{2}(2,4-\mathrm{D})_{4}\right.$ (phen) $]$ (phen $=1,10$-phenanthroline), ${ }^{[7]}\left[\mathrm{Cd}(2,4-\mathrm{D})_{2}(\mathrm{bib})\right]$ (bib=1,4-bis(imidazol-1-yl)-butane $)^{[24]}$ and $\left[\mathrm{Cd}(2,4-\mathrm{D})_{2}(4,4-\text { bipy })\right]_{\mathrm{n}}\left(4,4^{\prime}-\right.$ ${ }^{\mathrm{n}}$ Bipy $=4,4$ '-bipyridine $){ }^{[25]}$ The bond lengths of $\mathrm{Cd}(1)-\mathrm{O}(1), \mathrm{Cd}(1)-\mathrm{O}(4)$ are $2.370(2), 2.394(2) \AA$, respectively, which are comparable with those of other $\mathrm{Cd}(\mathrm{II})$ complexes. ${ }^{[25-27]}$ The bond angles of $\mathrm{O}(1)-\mathrm{Cd}(1)-\mathrm{O}(4), \mathrm{O}(4)-\mathrm{Cd}(1)-$ $\mathrm{O}(1 \mathrm{~A}), \mathrm{O}(1 \mathrm{~A})-\mathrm{Cd}(1)-\mathrm{O}(4 \mathrm{~A})$ and $\mathrm{O}(4 \mathrm{~A})-\mathrm{Cd}(1)-\mathrm{O}(1)$ are $103.40(8), 76.60(8)$, $103.40(8), 76.60(8)^{\circ}$, respectively, and the total value is $360^{\circ}$. These data mean that $\mathrm{Cd}(1), \mathrm{O}(1), \mathrm{O}(1 \mathrm{~A}), \mathrm{O}(4)$ and $\mathrm{O}(4 \mathrm{~A})$ atoms are coplanar and the $\mathrm{CdO}_{4} \mathrm{~N}_{2}$ geometry is a distorted octahedron.

It should be noted that the oxyacetate group is clearly twisted out of the plane of the benzene ring and the $\mathrm{C} 3-\mathrm{O} 3-\mathrm{C} 2-\mathrm{C} 1$ torsion angle is $-67.9(3)^{\circ}$. This indicates the remarkable conformational flexibility of 2,4-DH as compared with rigid aromatic carboxylic acid such as terephthalate ${ }^{[28]}$ Moreover, the characteristic $\mathrm{C}-\mathrm{O}_{\text {carboxylate }}$ bond lengths (Table 2) suggest electron delocalization of the carboxylate groups of the anionic ligands.

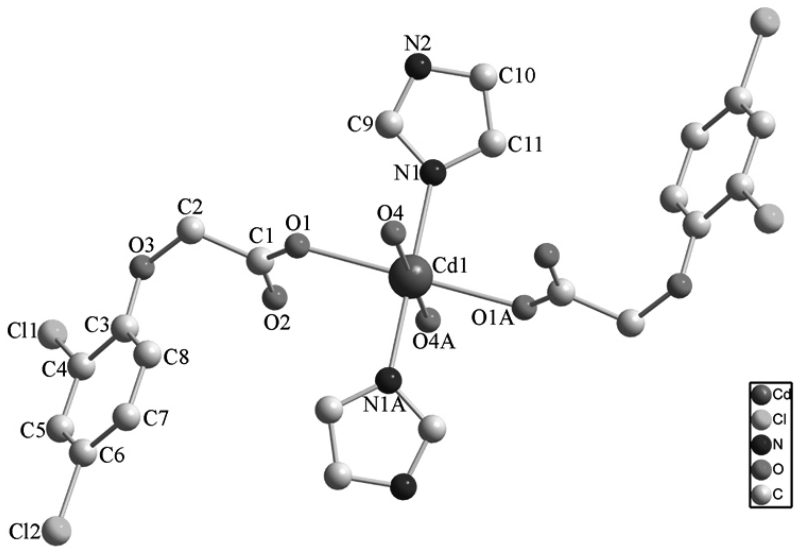

Figure 1 Molecular structure of the title complex, with hydrogen atoms omitted for clarity.

There are two types of intermolecular hydrogen bonds between the neighboring molecules (Table 3). An intermolecular $\mathrm{O}-\mathrm{H} \cdots \mathrm{O}$ hydrogen bond is formed between the uncoordinated carboxylate $\mathrm{O}$ atom and the $\mathrm{O}$ atom of the coordinated water molecule of the adjacent molecule, giving rise to a hydrogen-bonded chain along the $c$ axis. The other intermolecular hydrogen bond involves the uncoordinated carboxylate $\mathrm{O}$ atom and the $\mathrm{N}$ atom of imidazole molecule, leading to an $\mathrm{N}-\mathrm{H} \cdots \mathrm{O}$ hydrogen-bonded chain along the $b$ axis (Fig. 2). The chains crosslink each other and are further assembled through $\pi \cdots \pi$ stacking interactions between imidazole rings with centroid-to-centroid distance of $3.6235 \AA$, resulting in a two-dimensional supramolecular network (Fig. 3).

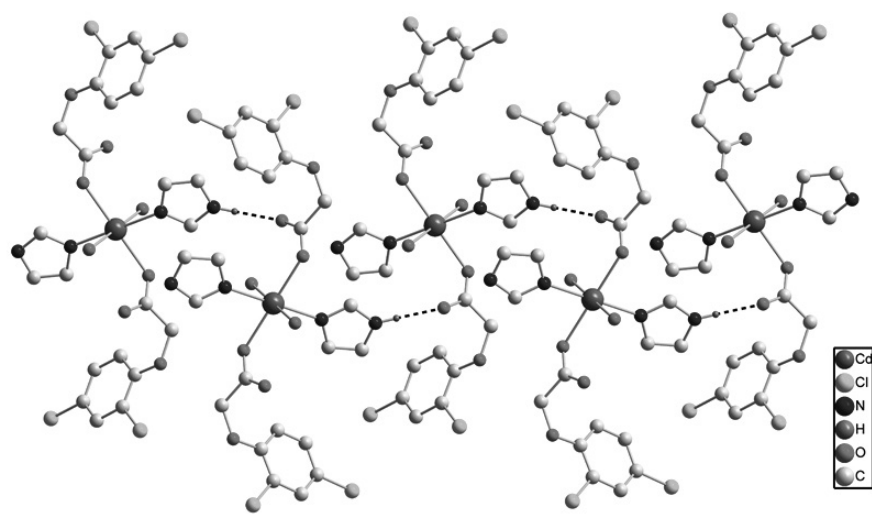

Figure $\mathbf{2}$ View of the chain structure in $\mathbf{1}$ formed by $\mathrm{N}-\mathrm{H} \times \times \times \mathrm{O}$ hydrogenbond. $\mathrm{H}$ atoms not involved in hydrogen bond have been omitted.

Table 3. Hydrogen bond geometries in the crystal structure of $\mathbf{1}$

\begin{tabular}{|c|c|c|c|c|}
\hline $\mathrm{D}-\mathrm{H} \cdots \mathrm{A}$ & $\mathrm{D}-\mathrm{H}[\AA]$ & $\mathrm{H} \cdots \mathrm{A}[\AA]$ & $\mathrm{D} \cdots \mathrm{A}[\AA]$ & $\mathrm{D}-\mathrm{H} \cdots \mathrm{A}\left[{ }^{\circ}\right]$ \\
\hline $\mathrm{N} 2-\mathrm{H} 2 \cdots \mathrm{O} 2^{\mathrm{a}}$ & 0.860 & 1.940 & 2.798 & 175.96 \\
$\mathrm{O} 4-\mathrm{H} 4 \mathrm{C} \cdots \mathrm{O} 2^{\mathrm{b}}$ & 0.850 & 1.945 & 2.788 & 171.37 \\
\hline
\end{tabular}

Symmetry code: (a) $-x+1, y-1 / 2,-z+3 / 2 ;$ (b) $-x+1,-y+1,-z+2$.

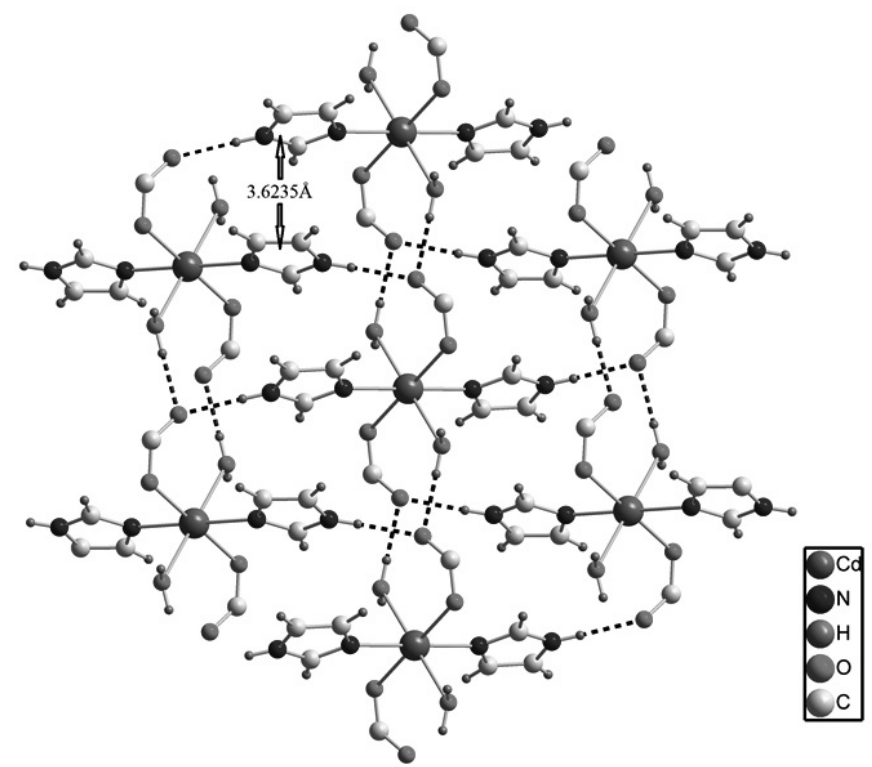

Figure 3 Packing diagram of 1 . Hydrogen bonds are indicated by black dashed lines. Only the carboxyl groups of 2,4-D ligands are kept for clarity.

We have previously reported the structure of $\left[\mathrm{Cu}_{2}(2,4-\mathrm{D})_{2}(\mathrm{Im})_{4}\right]_{\mathrm{n}}\left(\mathrm{NO}_{3}\right)_{2 \mathrm{n}}{ }^{19}$ In coordination polymer $\left[\mathrm{Cu}_{2}(2,4-\mathrm{D})_{2}(\mathrm{Im})_{4}\right]_{\mathrm{n}}\left(\mathrm{NO}_{3}\right)_{2 \mathrm{n}}$, the $\mathrm{Cu}(\mathrm{II})$ atoms are bridged by 2,4-dichlorophenoxyacetate, leading to an one-dimensional chain. The replacement of $\mathrm{Cu}(\mathrm{II})$ by $\mathrm{Cd}(\mathrm{II})$ results in a quite different structure of $\mathbf{1}$. These differences reveal that the metal ions play a crucial role in structural assembly. 


\subsection{Luminescent property}

It is known that $\mathrm{Cd}$ (II) complexes have high photoluminescence quantum yields and these complexes have potential applications in electroluminescent devices. ${ }^{[29]}$ Fig. 4 shows the excitation and emission spectra of the title complex in the solid state at room temperature. When the excitation wavelength is 280 $\mathrm{nm}$, the title complex exhibits an intense photoluminescence, and the maximum emission wavelength is at $455 \mathrm{~nm}$. Comparably, under similar conditions, two emission peaks at about $392 \mathrm{~nm}$ and $490 \mathrm{~nm}$ were observed for free imidazole and 2,4-DH, respectively. The emissions arising from the free ligands are not observed in the spectrum of compound 1. The absence of ligand-based emission suggests energy transfer from the ligands to the $\mathrm{Cd}(\mathrm{II})$ atoms during photoluminescence. Therefore, the photoluminescence can probably be assigned to the ligand-to-metal charge-transfer (LMCT) transition. ${ }^{[30]}$

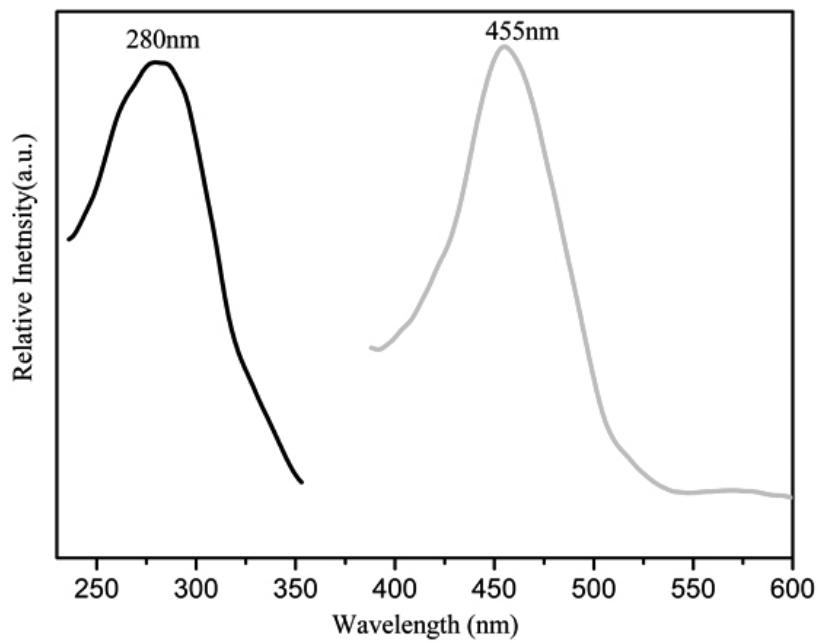

Figure 4 View of the excitation and emission spectra for $\mathbf{1}$ in the solid state at room temperature.

\section{CONCLUSIONS}

A novel Cadmium( II) complex, $\left[\mathrm{Cd}(2,4-\mathrm{D})_{2}(\mathrm{Im})_{2}\left(\mathrm{H}_{2} \mathrm{O}\right)_{2}\right]$, has been hydrothermally synthesized and structurally characterized. The complex falls into monoclinic system with space group of $P 2_{/} / c$. There exists two kinds of intermolecular hydrogen bonds and $\pi \cdots \pi$ interactions in the crystal which stabilize the structure. This work reinforces that weak intermolecular interactions play an important role in defining the overall supramolecular architecture.

\section{SUPPLEMENTARY MATERIAL}

Crystallographic data (cif) have been deposited with the Cambridge Structural Data Centre (CCDC) with reference number 880381. See http:// www.ccdc.cam.ac.uk/conts/retrieving.html for crystallographic data in cif or other electronic format. Copies of the data can be obtained, free of charge, on application to CCDC, 12 Union Road, Cambridge CB2 1EZ, UK [fax: 44(0)1223-336033 or E-mail: deposit@ccdc.cam.ac.uk].

\section{ACKNOWLEDGMENTS}

This work was financially supported by Scientific Research Foundation of anhui Provincial Education Departament (KJ2014A228).

\section{REFERENCES}

1. J. Wang, L. Lu, W. P. Wu, B. Xie, Synth. Reac. Inorg. Met.-Org. NanoMet. Chem. 42, 25, (2012).

2. Y. Bing, X. Li, M. Q. Zha, D. J. Wang, Synth. Reac. Inorg. Met.-Org. Nano-Met. Chem. 41, 798, (2011).

3. J. Q. Liu, J. Wu, T. Wu, Synth. Reac. Inorg. Met.-Org. Nano-Met. Chem. 40, 231, (2010).

4. B. Yıldırım, T. Yeşiloğlu, M. İncesu, M. U. Kamiloğlu, B. Çimen, Ş. Tamer, New Zeal. J. Crop. Hort. 40, 55, (2012).

5. S. Z. Liu, Acta Crystallogr. E66, m621, (2010).

6. B. Ptaszynski, A. Zwolinska, J. Therm. Anal. Calorim. 75, 301, (2004).

7. Y. Q. Yang, C. H. Li, W. Li, Y. F. Kuang, Chin. J. Inorg. Chem. 25, 1120 , (2009).

8. G. Smith, E. J. O'Reilly, C. H. L. Kennard, Inorg Chim Acta. 49, 53, (1981).

9. W. D. Song, D. L. Xi, Acta Crystallogr. E62, m2594, (2006).

10. D. Y. Ma, H. F. Guo, K. Lu, Y. Pan, L. Qin, J. Coord. Chem. 65, 1610, (2012).

11. W. Chen, J. W. Yuan, L. Lei, Q. F. Zeng, Acta Crystallogr. E65, m1148, (2009).

12. W. D. Song, X. H. Huang, J. B. Yan, D. Y. Ma, Acta Cryst. E64, m654, (2008).

13. C. Dendrinou-Samara, D. Drosou, L. Iordanidis, A. Terzis, D. P. Kesissoglou, J. Inorg. Biochem. 92, 156, (2002).

14. S. M. Shi, Z. F. Chen, Y. C. Liu, L. Mao, H. Liang, Z. Y. Zhou, J. Coord. Chem. 61, 2725, (2008).

15. J. W. Liu, B. Zhu, Y. Tian, C. S. Gu, Acta Crystallogr. E62, m2030, (2006).

16. Z. P. Li, Y. H. Xing, Y. Z. Gao, X. Q. Zeng, M. F. Ge, S. Y. Niu, Polyhedron. 28, 865, (2009).

17. C. Dendrinou-Samara, G. Psomas, L. Iordanidis, V. Tangoulis, D. P. Kessissoglou, Chem. Eur. J. 7, 5041, (2001).

18. P. Y. Huang, J. G. Wang, Acta Crystallogr. E63, m645, (2007).

19. Y. H. Zhou, Y. P. Tian, J. Y. Wu, J. Synthetic. Cryst. 38, 974, (2009).

20. W. Li, C. H. Li, Y. Q. Yang, S. H. Zhang, Y. L. Li, Chin. J. Inorg. Chem. 25, 369, (2009).

21. Sheldrick, G. M. SADABS, A program for empirical absorption correction of area detector data. University of Göttingen: Germany, 1997.

22. Sheldrick, G. M. SHELXS 97, Program for crystal structure solution. University of Göttingen: Germany, 1997.

23. K. Nakamoto, Infrared Spectra and Raman Spectra of Inorganic and Coordination Compound. John Wiley \& Sons: New York, 1986.

24. Y. H. Zhou, Y. P. Tian, J. Chem. Crystallogr. 43, 31, (2013).

25. H. F. Guo, D. Y. Ma, L. Qin, P. Yan, Russ. J. Coord. Chem. 39, 58, (2013).

26. H. S. Wang, W. Shi, B. Zhai, J. G. Ma, J. Xia, P. Cheng, J. Mol. Struct. 833, 102, (2007).

27. L. L. Wen, Y. Z. Li, Z. D. Lu, J. G. Lin, C. Y. Duan, Q. J. Meng, Cryst. Growth Des. 6, 530, (2006).

28. H. B. Xu, Z. M. Su, K. Z. Shao, Y. H. Zhao, Y. Xing, Y. C. Liang, H. J. Zhang, D. X. Zhu, Inorg. Chem. Comm. 7, 260, (2004).

29. Y. Q. Yang, C. H. Li, W. Li, Y. F. Kuang, Chin. J. Inorg. Chem. 26, 1890, (2010)

30. S. Kitagawa, R. Kitaura, S. Noro, Angew. Chem. Int. Ed. 43, 2334, (2004). 